JOURNAL of

MAINE MEDICAL CENTER Journal of Maine Medical Center

Volume 2

Issue 1 Volume 2, Issue 1 (January 2020)

Article 13

2020

\title{
The Maine Medical Center-Preble Street Learning Collaborative (PSLC): An Example of Community Led Transformation of Care
}

Peter Bates MD

Tufts University School of Medicine

Et al.

Follow this and additional works at: https://knowledgeconnection.mainehealth.org/jmmc

\section{Recommended Citation}

Bates MD, Peter; Swann MSPA, Mark R.; and Kruithoff RN, MS, Catherine (2020) "The Maine Medical Center-Preble Street Learning Collaborative (PSLC): An Example of Community Led Transformation of Care," Journal of Maine Medical Center. Vol. 2 : Iss. 1 , Article 13.

Available at: https://knowledgeconnection.mainehealth.org/jmmc/vol2/iss1/13 https://doi.org/10.46804/ 2641-2225.1037

The views and thoughts expressed in this manuscript belong solely to the author[s] and do not reflect the opinions of the Journal of Maine Medical Center or MaineHealth.

This Commentary is brought to you for free and open access by Maine Medical Center Department of Medical Education. It has been accepted for inclusion in the Journal of Maine Medical Center by an authorized editor of the MaineHealth Knowledge Connection. For more information, please contact Dina McKelvy mckeld1@mmc.org.

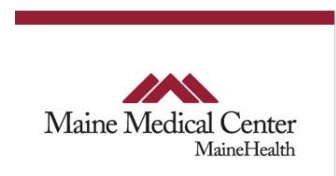


The Maine Medical Center-Preble Street Learning Collaborative (PSLC): An Example of Community Led Transformation of Care

\section{Authors}

Peter Bates MD; Mark R. Swann MSPA; and Catherine Kruithoff RN, MS 


\title{
The Maine Medical Center Preble Street Learning Collaborative: An Example of Community Led Transformation of Care
}

\author{
Peter Bates MD, ${ }^{1}$ Mark Swann MSPA, ${ }^{2}$ Catherine Kruithoff RN, $\mathrm{MS}^{3}$ \\ ${ }^{1}$ Tufts University School of Medicine, Boston MA, ${ }^{2}$ Preble Street, Portland, ME, ${ }^{3}$ Department of Medical Education, Maine \\ Medical Center, Portland, ME
}

\begin{abstract}
Mark Swann: When my colleagues around the country learn of the Preble Street Learning Collaborative (PSLC), they are envious. Social service agencies, such as Preble Street in Portland, Maine, dream of having a strong, sustainable, and committed partnership with their neighboring hospital. Preble Street's mission is to provide accessible, barrier-free services that empower people experiencing problems with homelessness, housing, hunger, and poverty; and to advocate for solutions to these problems. Too often, there is little or no collaboration between hospitals, public-health organizations, and community organizations who know this population well and work daily with those living on the streets or in a homeless shelter.
\end{abstract}

People experiencing homelessness have limited access to health care. As a result, communityrun resource centers and homeless shelters have become de facto emergency rooms, respite facilities, and even hospice care providers. After Portland's longtime health program for the homeless abruptly closed, Preble Street staff saw overwhelming individual needs. We were unprepared to respond and bridge gaps in health care services. Preble Street asked Maine Medical Center (MMC) for help. Peter Bates, MMC's Chief Medical Officer, assured us that he wanted to collaborate to solve some of these problems. Preble Street and MMC are experts in their work. As partners, we knew we could develop sustainable solutions to the challenges we saw in our community.

Correspondence: Catherine Kruithoff RN, MS

Dept. of Medical Education, Maine Medical Center

335 Brighton Ave, Portland ME 04102

KRUITC@mmc.org
Peter Bates and Catherine Kruithoff:

Transformationalchange inhealthcareis challenging in any established culture or organization. John P. Kotter, a Harvard Business School professor, published a paper on why organizational change fails. ${ }^{1}$ Based on these observations, he developed an eight-stage process for major change, part of which we used to illustrate the development of the PSLC (Figure 1).

\section{Establish a sense of urgency}

In 2014, Portland experienced an economic recession that worsened the plight of those experiencing homelessness. The City of Portland Homeless Health Care Clinic closed, and the state of Maine deferred Medicaid expansion. At the same time, the Accreditation Council for Graduate Medical Education (ACGME) began to stress education about health care disparities and culturally sensitive care in residencies. MMC also experienced an increase in emergency department visits and extended hospitalizations related to people experiencing homelessness. These events, and the reality of this human crisis, were captured in an emotional presentation given by Mark Swann at an MMC medical education retreat. Mark shared a story about the struggles of a homeless person from the early days of Preble Street. The story energized everyone who attended, including medical education leaders and learners. Kotter reminds us that in successful change initiatives, data are important, but stories help fuel the will to change. 


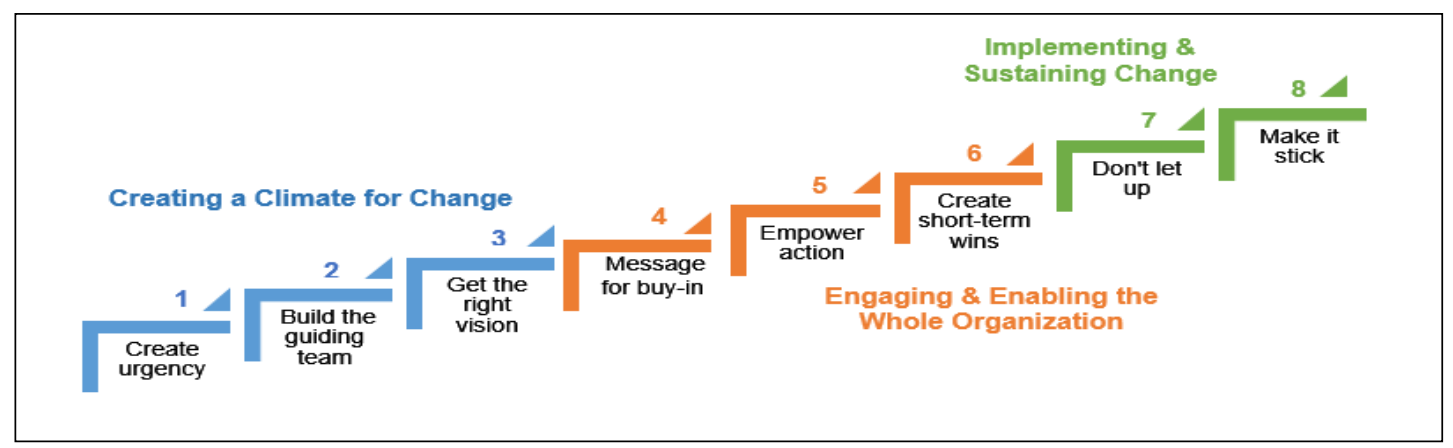

Figure 1. Kotter Eight-Stage Process of Creating Major Change (adapted) ${ }^{1}$

Framing the urgency of MMC's overall vision and strategy helped ensure that the organization had broad appeal and support to:

- Improve population health:The health status of those experiencing homelessness was significantly worse than the general population.

- Enhance the patient experience: People experiencing homelessness had limited access to primary and specialty care, resulting in poor outcomes.

- Increase the well-being of the care team: Graduate medical education learners and faculty wanted opportunities to engage in the care of vulnerable populations.

- Reduce per capita cost of care: Poor access and fragmentation of care led to increased health care use, driving higher cost.

Everyone in health care abhors human suffering. But we have different backgrounds and responsibilities, and thus see crises differently. By characterizing the urgency in a balanced way, we created a stronger case.

\section{Build a guiding coalition}

A successful change initiative needs a diverse and powerful coalition with a shared commitment to change. This stage takes time. We needed to engage both an internal and external coalition, and to meet with key leaders to hear their concerns and ideas. Our internal coalition contained a core group of educators, learners, and clinicians who took ownership and pushed the initiative forward. We interviewed key senior leaders at MMC to leverage their expertise and elicit their support.
We also invited community stakeholders to meet and discuss how MMC might help. Initially, it was a challenging environment-finger-pointing constrained collaboration. At MMC, we needed to engage with people who had decades of experience working with vulnerable populations. After several conversations, the external coalition united around the needs of our homeless community.

At MMC, we initially envisioned launching a primary care clinic, but our external coalition highlighted that medical homes serving this population already existed. Creating an additional clinic site could contribute to chaos and fragmentation of care. Thus, we shifted the focus, emphasizing low-barrier access to coordinating complex care and educating future health care providers.

\section{Create a vision and strategy}

We needed a vision for the PSLC that could be easily understood and embraced by everyone. By focusing on the education of future health care providers, the introduction of needed "gap" services and care coordination for vulnerable populations allowed MMC to contribute expertise while respecting and supporting community stakeholders.

PSLC strategies included creating a culturally sensitive curriculum that stressed experiential, interprofessional learning focused on social determinants of health; provided intensive, lowbarrier case management to reduce fragmentation of care; facilitated engagement with existing medical homes; and offered new services, such as mental health, select specialty, and dental care.

Before implementation, we tested our proposed PSLC vision and strategy by asking four critical questions key to successful disruptive innovations: ${ }^{2}$ 
- Is it simple? Providing education in health disparities as part of the care process aligns curricular and community goals.

- Is it cheaper? Reducing avoidable admissions and extended hospital stays will reduce health care costs and help support the program.

- Is it "solution-oriented"? Intensive case management and new clinical services provide timely care and limit suffering.

- Is this proposal supported or inhibited by regulation? By complying with existing accreditation standards and not billing for services, regulations did not present any barriers.
Mark, Peter and Catherine: Is the PSLC an example of disruptive innovation in health care?

Disruptive or not, ideas for radical change are needed to meet the health care needs of our communities. As leaders, we are responsible for finding, testing, and implementing innovations that promise better and less-expensive care for everyone. Collaborations like the PSLC are untapped opportunities that leverage existing expertise, resources, and the will to help vulnerable people in our communities. If successful, these ideas can provide a safe place for people to heal, regain stability, and reclaim a sense of what is possible for their lives.

Homelessness is gruesome and painful. But at the PSLC, hope lives.

\section{REFERENCES}

1. Kotter, JP. Leading Change. Boston, MA: Harvard Business Review Press; 012.

2. Hwang J, Christensen CM. Disruptive innovation in health care delivery: a framework for business-model innovation. Health Aff (Milwood). 2008;27(5):1329-1335. doi:10.1377/ hlthaff.27.5.1329 